\title{
Investigation of Loss of Consciousness Induced by Gravity Acceleration on the Human Brain
}

\author{
Abbas Shafiee $^{1 *}$, Amirhossein Ahmadian², Mohammadali Alidoost ${ }^{3}$ \\ ${ }^{1}$ School of Mechanical Engineering, Purdue University, West Lafayette, USA \\ ${ }^{2}$ Department of Mechanical and Aerospace Engineering, University of California, Los Angeles, USA \\ ${ }^{3}$ Department of Bioengineering, University of California, Los Angeles, USA \\ Email: *shafiee@purdue.edu
}

How to cite this paper: Shafiee, A., Ahmadian, A. andAlidoost, M. (2021) Investigation of Loss of Consciousness Induced by Gravity Acceleration on the Human Brain. Open Access Library Journal, 8: e7507.

https://doi.org/10.4236/oalib.1107507

Received: May 10, 2021

Accepted: June 27, 2021

Published: June 30, 2021

Copyright $\odot 2021$ by author(s) and Open Access Library Inc.

This work is licensed under the Creative Commons Attribution International License (CC BY 4.0).

http://creativecommons.org/licenses/by/4.0/

\begin{abstract}
Traumatic Brain Injuries (TBI's) are any disorder in a brain's functionality that can be caused by numerous reasons, including motor-vehicle crashes, falls, and assaults. Impractical in-vivo head injury experiments compel bioengineers to develop a robust, accurate, and efficient computer model. In this study, bovine brain samples were tested under a confined compression testing machine. Consequently, the result from unconfined compression tests, at quasi-static strain rates of $\dot{\varepsilon}=0.0004 \mathrm{~s}^{-1}, \dot{\varepsilon}=0.008 \mathrm{~s}^{-1}$, and $\dot{\varepsilon}=0.4 \mathrm{~s}^{-1}$, and a stress relaxation test under unconfined uniaxial compression with a $\dot{\varepsilon}=0.67 \mathrm{~s}^{-1}$ ramp rate were utilized for fitting brain tissue model. The tissue model employs Drucker stability criteria and conventional hyperelastic models. A finite element model was also developed and validated by experimental data to examine the experiments' friction effect. Furthermore, the extracted brain tissue model was employed in a 3D head injury model. The 3D model was employed to examine the effect of $+G_{z}$ acceleration on the human brain and present damage threshold based on loss of consciousness in HIC and Maximum Brain Pressure criteria. It is shown that the relative difference between simulation results at friction coefficient of $\mu=0.5$ and $\mu=0.0$ are less than $20 \%$, and the ramp rate variation has a slight effect on normalized shear modulus. Moreover, Head modeling results revealed that the Maximum Brain Pressure $\geq 3.1 \mathrm{KPa}$ and $\mathrm{HIC} \geq 30$ are a representation of loss of consciousness.
\end{abstract}

\section{Subject Areas}

Anatomy \& Physiology, Applications of Communication Systems, Bioengineering 


\section{Keywords}

Brain Tissue, Viscohyperelastic, Finite Element Analysis (FEA),

TBI (Traumatic Brain Injury), G-Acceleration, Damage Criteria

\section{Introduction}

Introduction Traumatic Brain Injury (TBI) is a disruption in the brain's normal function resulting from a blow or jolt to the head or an object penetrating brain tissue. TBI can have a wide range of physical and psychological effects including mild, moderate, and severe categories. The USA's Centers for Disease Control and Prevention (CDC) reports that about 155 Americans die from Traumatic Brain Injuries (TBI)-related injuries each day in 2014 [1]. In a space mission where an astronaut's brain is exposed to quasi-static and dynamic strain rates, the risk of TBI is increased. TBIs are one of the leading causes of death or disability [2] [3]. Pilots flying high-performance aircraft are exposed to loss of consciousness due to the $+G_{z}$ forces and its consequent high acceleration. There are actual reports in the US and United Kingdom Royal Air Forces confirming such cases [4]. The importance of this matter compels bioengineers to predict the cause and effect of TBI. It is crystal clear that in-vivo experiments are not practical in the realm of TBI.

Ergo, the Finite Element Method (FEM) offers a cost-effective alternative [5] [6] [7] [8] [9] in bio-mechanical [10]-[17] and specifically human injury research [18]. Dynamic responses of brain tissues are required to model the head injury and foresee TBI accurately. Nevertheless, the relationship of skull kinematics and the tissue responses causing TBIs is not intuitional due to the fact that brain can deform with complicated and non-linear material properties as well as complex brain-skull boundary conditions [19] [20] [21].

Literature shows that the brain, like most tissues in our body, is a viscohyperelastic material, directionally changes [22] [23] and are time dependent [24].

There are a lot of researches to identify the complex mechanical behavior of structural materials, experimentally and analytically; however, there is not much in the area of biomechanics as to working with live tissues [25]-[33].

McCarty in her thesis tried to characterize the mechanical properties of brain tissues during and after blast induced TBIs in a stress relaxation experiment. The effect of blast impact and swelling were explored by exposing the porcine brains to a shock wave generated by an air pistol and soaking them in a container with saline solution, respectively. The results from this work extended the information about the dynamic mechanical behavior of brain tissue [34].

Menichetti et al. applied up to $35 \%$ strain at $10 \mathrm{~s}^{-1}$ strain rate to 12 different regions of the human brain to assess the mechanical behaviors of several brain regions. Their results demonstrated that there are statistically significant differences between regions; however, age, sex, and time post-mortem had no effect 
[35].

A study has been done by Li et al., where a uniaxial compression tests at strain rates of $0.01 \mathrm{~s}^{-1}, 1 \mathrm{~s}^{-1}$, and $50 \mathrm{~s}^{-1}$ up to $50 \%$ strain were performed for the corona radiata, corpus callosum, thalamus, cortex, cerebellum, and brainstem. They concluded that there is no considerable difference in tissue strength among the cerebrum regions of cortex, thalamus, corona radiata, and corpus callosum. Moreover, outcomes show that the one-term Ogden constitutive model can well represent the compressive behavior of the brain tissue at different strain rates [36].

Mihai et al. conducted a myriad of multiaxial shear, tension, and compression tests to systematically delve into the brain's mechanical behaviors' time-dependent characteristics. They recognized that an isotropic modified one-term Ogden model is suitable for representing the hyperelastic behavior under a combined loading condition [37]. However, other alternative hyperelastic models could be adopted [38].

Teferra and Brewick conducted a study to specify parameter distributions of brain tissue data illustrating the mechanical properties by considering the hyperviscoelastic constitutive model as well as multiple loading configurations using a Bayesian calibration approach. Their results showed that by following this approach, a more in-depth parameter variation analysis and model calibration can be achieved [39].

From the head model perspective of this paper, some 3D head models were developed for different investigations and Targets. Ruan et al. applied an impact to Wayne State University Head Injury Model (WSUHIM) (introduced in 1993). They showed a relationship between contrecoup pressure, maximum shear stress, the severity of impact, and brain injury [40]. Using Simulated Injury Monitor (SIMon) human finite element head model, Zhang et al. to investigate head injury induced by linear and rotational acceleration. Rotational acceleration was found to play a significant role in the head injury mechanism [41].

Shi et al. employed the THUMS (Ver. 4.0.2) finite element model to reconstruct vulnerable road users' kinematics vehicle collisions (ground impacts) using the video records to evaluate different head kinematics-based injury risks criteria by deriving various brain tissue severe injury thresholds. They concluded that angular acceleration, linear acceleration, head injury criterion (HIC), coup pressure (C.P.), maximum principal strain (MPS), and cumulative strain damage measure (CSDM) were able to predict $75 \%-100 \%$ of the accident [42].

Stephanie A. Pasquesi et al. measured brain-skull displacements from a myriad of sagittally transected piglet heads subjected to sagittal plane rotations, developed a finite element model imitating the geometry of the sagittally transected piglet head, and determined a brain-skull boundary condition in the finite element model that was well in agreement with finite element displacements to experimentally extracted value [43].

To model a 3D human head and predict TBI at a quasi-static strain rate, one needs the accurate viscohyperelastic constitutive model based on the investiga- 
tion's application and targets. As literature shows, there are different reports for brain tissue's mechanical properties, and no studies have been carried out, to our best knowledge, to investigate head damage due to pressure resulting from $+G_{z}$ acceleration and report loss of consciousness based on Max. Brain Pressure and HIC criteria.

This study aims to present a suitable viscohyperelastic model with consideration of Drucker stability criteria and study the effect of friction coefficient and ramp rate on experimental results. In this paper, relaxation and unconfined compression tests are conducted on cylindrical specimens of bovine brain tissue under compression up to $30 \%$ strain at strain rates of $\dot{\varepsilon}=0.0004 \mathrm{~s}^{-1}, \dot{\varepsilon}=0.008 \mathrm{~s}^{-1}$, and $\dot{\varepsilon}=0.4 \mathrm{~s}^{-1}$ for the compression and $\dot{\varepsilon}=0.67 \mathrm{~s}^{-1}$ ramp rate with $80 \mathrm{~s}$ holding time for the relaxation. The hyperelastic parameters corresponding to Baltz-Co, Fung, Gent, Van Der Waals, Arruda-Boyce, Ogden, Polynomial, and Reduced Polynomial strain energy function are obtained, and viscoelastic parameters corresponding to the Prony series were extracted.

In order to validate viscohyperelastic parameters, Finite Element Analysis (FEA) was employed where it matches nicely with experimental findings. Activities in these regards serve the implication in neurosurgery, haptic device design, and human head modeling, where an accurate mechanical characterization of brain tissue is of crucial importance.

Hence, this paper's next step is an investigation of the loss of consciousness threshold from $+G_{z}$ acceleration using head damage criteria such as HIC and maximum brain pressure based on a developed 3D finite element head model. Results revealed that Max. Brain Pressure $\geq 3.1 \mathrm{KPa}$ and HIC $\geq 30$ represents loss of consciousness, and 3D plots are provided to depict the loss of consciousness based on Max. Brain Pressure and HIC criteria.

The paper is structured as follows: Section 2 introduces Material and Method, including the experiment procedure and the governing equations for hyperviscoelastic material. In addition, a 3D finite element head model is presented. In Section 3, results and discussions for unconfined compression tests and relaxation tests are presented, and required representative constants for brain tissue hyperviscoelasticity are extracted. A finite element simulation was conducted for brain specimens to compare the brain-behavior with experimental results under extracted hyperelastic constants. After validating this finite element model, we explored the friction coefficient's effect on the unconfined compression tests and ramp rate variation on relaxations tests. In addition, a $3 \mathrm{D}$ finite element of the head model is presented in Section 2 and is tested under different $+G_{z}$ accelerations. Loss of consciousness is expressed in terms of HIC criteria and Maximum Brain Pressure in a 3D domain afterward. And finally, the paper is concluded in Section 4.

\section{Materials}

\subsection{Specimen Preparation}

In vitro human brain tissue studies are hard to conduct; therefore, animal brain 
samples (such as monkey, porcine, bovine, and rat) are being used for the tests. Considering various animals' brain tissue, studies have also showed that there is not any difference between the in vitro dynamic mechanical response [44] [45]. In this study, the fresh bovine brain is collected from the slaughterhouse. Brain sample preparation is in accordance with our previous work [46] [47]. Conducted experiments and sample preparations were within the animal welfare guidelines and regulations. The cylindrical specimen brain is shown in Figure 1.

The samples include a mixed white and gray matter. There is extensive work to look into the white and gray matter separately to differentiate white and gray matter properties and define accurate mechanical properties [48] [49] [50]. However, at low strain and strain rate, the white and gray matter can be assumed to be homogeneous and isotropic [51].

\subsection{Experimental Setup}

Unconfined compression tests were conducted on cylindrical cerebral specimens using a Hounsfield H10KS testing machine, equipped with a servomotor for displacement shown in Figure 2(a). The testing machine enables us to apply uniform velocity during the compression of tissue in the axial direction. This testing machine is directly connected to a computer. Force and displacement were recorded in real-time manner.

\section{Methods}

\subsection{Unconfined Compression Tests}

Unconfined compression tests are performed on bovine brain cylindrical specimens up to $30 \%$ strain. The velocity of the compression platen (top platen) is

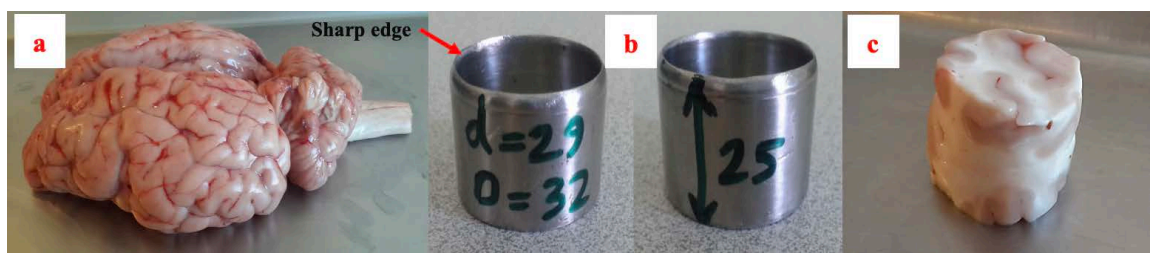

Figure 1. (a) The prepared bovine brain; (b) Steel pipe for cutting brain specimen; and (c) The cylindrical Specimen brain [46] [47].

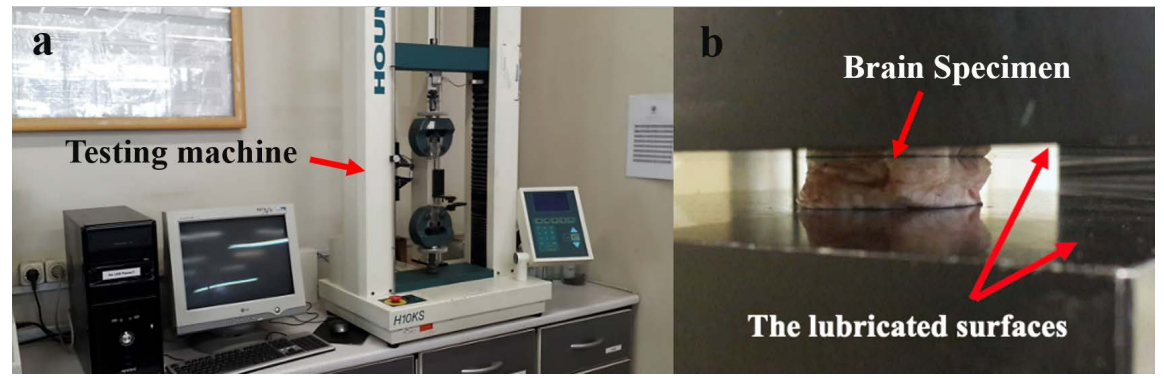

Figure 2. (a) Hounsfield H10KS testing machine; (b) The brain specimen under unconfined compression [46] [47]. 
adjusted to $0.6 \mathrm{~mm} / \mathrm{min}$ (slow), $12 \mathrm{~mm} / \mathrm{min}$ (medium), and $600 \mathrm{~mm} / \mathrm{min}$ (fast) corresponding to approximate strain rates of $0.0004,0.008$, and 0.4 , respectively. Ten unconfined compression tests were performed at strain rates of 0.0004 and 15 at strain rates of each 0.008 and 0.4 . Some sample preservation measures taken before doing unconfined compression tests are listed in our previous studies [46] [47]. Figure 2(b) shows the brain specimen under unconfined compression [46] [47].

\subsection{Relaxation Tests}

A separate relaxation test was performed on bovine brain cylindrical specimens up to $30 \%$ strain. Also, ten relaxation tests were performed under finite stepand-hold uniaxial compression with $0.67 \mathrm{~s}^{-1}$ ramp rate and $80 \mathrm{~s}$ hold time. The average rise time, measured from the force relaxation experiments, was $450 \mathrm{~ms}$.

\subsection{Phenomenological Constitutive Models}

\subsubsection{Hyperelastic Constitutive Models}

Mechanical properties of some materials, such as modulus of elasticity, strongly depend on the rate of applying load. Usually, these materials have non-linear behavior with strain and strain rate dependence. These materials are categorized as hyperelastic.

\section{Preliminaries}

An elastic-free energy potential can derive a constitutive response called Hyperelasticity which can be utilized for the materials experiencing sizeable elastic deformation. Applications for elastomers such as vulcanized rubber and synthetic polymers, along with some biological materials, often fall into this category [52]. There are several strain energy potentials associated with hyperelastic materials, namely: Arruda-Boyce, Ogden, polynomial, reduced polynomial, Van der Waals, Fung, Gent, and Baltz-Ko hyperelastic models. These models are going to used and fitted to experimental results to reveal which one can be a best hyperelasticity description of the brain tissue for our experiments. Four our future use, the $2^{\text {nd }}$ order reduced polynomial hyperelastic model is described here.

\section{Second-order Reduced Polynomial Strain Energy Function}

The hyperelastic $2^{\text {nd }}$ order reduced polynomial strain energy function $U$ for the incompressible isotropic material is as follows:

$$
U=\sum_{i=1}^{N} C_{i 0}\left(I_{1}-3\right)^{i}
$$

In Equation (1), where $C_{i 0}$ is a temperature-dependent material parameter which should be positive (for the satisfaction of Drucker stability), $I_{1}$ first strain invariant, and $\mu_{0}$ is the initial shear modulus. $I_{1}$ and $\mu_{0}$ are:

$$
\begin{gathered}
I_{1}=\lambda_{1}^{2}+\lambda_{2}^{2}+\lambda_{3}^{2}=\lambda_{U}^{2}+2 \lambda_{U}^{-1} \\
\mu_{0}=2 C_{10}
\end{gathered}
$$

where $\lambda_{U}$ is a stretch. Then the nominal stress $T_{U}$ is [53]: 


$$
T_{U}=2\left(\lambda_{U}-\lambda_{U}^{-2}\right) \sum_{i=1}^{N} i C_{i 0}\left(I_{1}-3\right)^{i-1}
$$

It should be noted that the Drucker stability criterion is a strong condition on the incremental internal energy of a material, which states that the incremental internal energy can only increase [54].

\subsubsection{Prony Series for Viscoelastic Material}

The Prony series can express the shear relaxation modulus $(G(t))$ of a viscoelastic material.

$$
G(t)=G_{\infty}+\sum_{i=1}^{N} G_{i} \exp \left(-\frac{t}{\tau_{i}}\right)
$$

where $\tau_{i}, G_{i}$, and $G_{\infty}$ are relaxation times, relaxation modulus constants, and long-term shear modulus, respectively. If $G(0)=G_{0}=G_{\infty}+\sum_{i=1}^{N} G_{i}, g_{i}=\frac{G_{i}}{G_{0}}$, then:

where is normalized shear modulus $g(t)$ can be written as:

$$
g(t)=g_{\infty}+\sum_{i=1}^{N} g_{i} \exp \left(-\frac{t}{\tau_{i}}\right)
$$

since,

$$
1=g_{\infty}+\sum_{i=1}^{N} g_{i}
$$

the Equation (6) can be arranged to look like

$$
g(t)=1+g_{\infty}+\sum_{i=1}^{N}\left[g_{i} \exp \left(-\frac{t}{\tau_{i}}\right)-1\right]
$$

Specifically for two terms of viscoelastic Prony series, we have:

$$
g(t)=1-\left(g_{1}+g_{2}\right)+g_{1} \exp \left(-\frac{t}{\tau_{1}}\right)+g_{2} \exp \left(-\frac{t}{\tau_{2}}\right)
$$

\subsection{Three Dimensional Finite Element Head Model Development}

In this section, a 3D finite element head model is presented. Our model is composed of three parts, including skull, meningeal layer, and brain.We have used the 3D human head model developed in our previous work [55] [56].

The material properties implemented in the model are presented in Table 1. In order to describe the hyperelastic and viscoelastic mechanical behavior of the

Table 1. The implemented mechanical properties of the skull, meningeal layer, and brain tissues in our 3D FE model.

\begin{tabular}{ccccccc}
\hline \multirow{2}{*}{ Tissue } & Mechanical Behavior & $\begin{array}{c}\text { Density } \\
\left(\mathrm{Kg} / \mathrm{m}^{3}\right)\end{array}$ & $\begin{array}{c}\text { Young's Modulus } \\
(\mathrm{KPa})\end{array}$ & $\begin{array}{c}\text { Shear Modulus } \\
(\mathrm{KPa})\end{array}$ & Poisson Ratio & Reference \\
\hline \multirow{2}{*}{$\begin{array}{c}\text { Skull } \\
\text { Meningeal layer }\end{array}$} & Ligid isotropic & 2080 & N/A & N/A & N/A & {$[57]$} \\
Brain & Viscohyperelastic, incompressible isotropic & 1040 & N/A & N/A & 0.499 & {$[59]$} \\
\hline
\end{tabular}


tissue, the $2^{\text {nd }}$ order reduced polynomial hyperelastic model and the Prony series were used.

The parameters of the $2^{\text {nd }}$ order reduced polynomial viscohyperelastic model used for three dimensional head model will be presented in the results section, as a finding from unconfined compression tests.

Our previous work [55] explains well the mesh properties, boundary conditions between the skull, meningeal layer, and brain and provides model validation using literature [60] [61] [62] [63].

\section{Results and Discussion}

\subsection{Unconfined Compression Tests}

The experimental data for slow, medium and fast strain rate are shown in Figures $3(a)-(c)$, respectively. In these figures and similar figures in this paper, solid
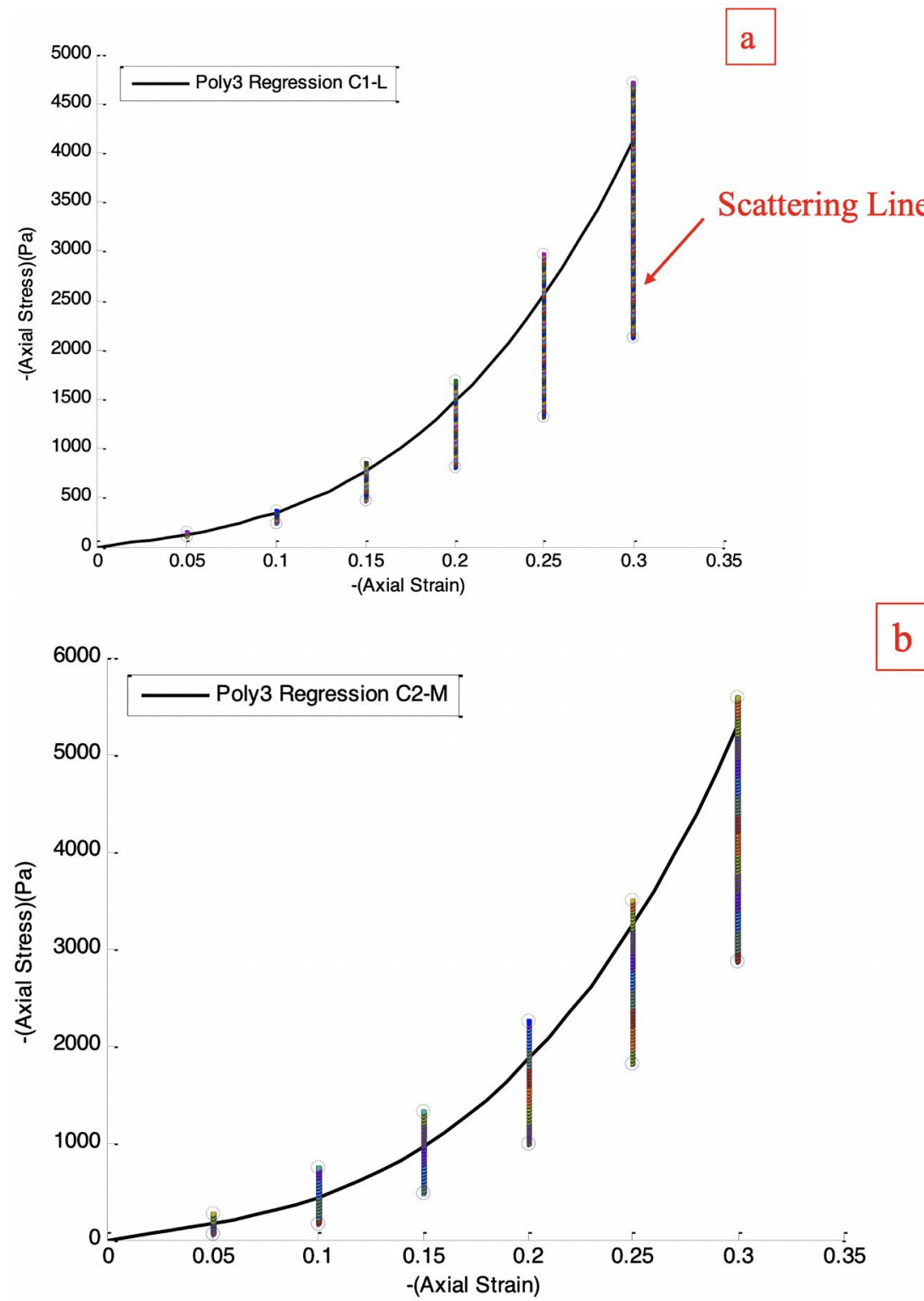


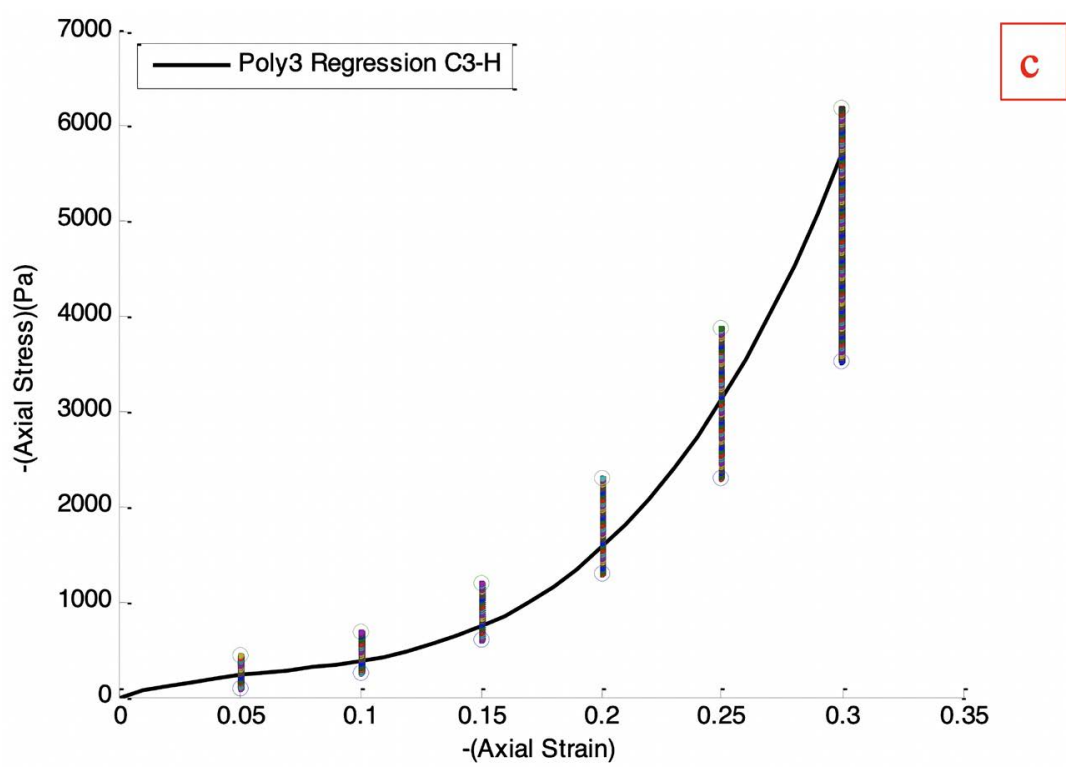

Figure 3. Experimental results for the compression of brain tissue at various loading velocities. (a) Loading velocity of $0.6 \mathrm{~mm} / \mathrm{min}$ (slow), corresponding to a strain rate of 0.0004 . (b) Loading velocity of $12 \mathrm{~mm} / \mathrm{min}$ (medium), corresponding to the strain rate of 0.008 . (c) Loading velocity of $600 \mathrm{~mm} / \mathrm{min}$ (fast); corresponding to the strain rate of 0.4 .

curves are the mode of experimental results, and vertical lines are scattering line at the specific axial strain. The stress-strain curves are concave upward for all compression rates, and by increasing strain rate, the brain tissue becomes stiffer.

\subsection{Relaxation Experimentation}

Stress versus time for relaxation test with $0.67 \mathrm{~s}^{-1}$ ramp rate and $80 \mathrm{sec}$. Hold time is shown in Figure 4.

As can be seen in Figure 4, stress increases in a short period and relaxes afterward.

\subsection{Fitting of Constitutive Hyperelastic Models to Unconfined Compression Test Result}

The material coefficients of the hyperelastic models are calibrated by lsqcurvefit function in MATLAB ${ }^{\circledR}$ from experimental stress-strain data at a slow rate. This function minimizes the relative error in stress [64]. For the nominal stress-nominal strain data pairs, the relative error $\mathrm{E}$ was minimized, where:

$$
E=\sum_{i=1}^{N}\left(1-\frac{T_{i}^{U}}{T_{i}^{\text {test }}}\right)^{2}
$$

$T_{i}^{\text {test }}$ 's are stress value from the test data and $T_{i}^{U}$ 's come from one of the nominal stress expressions derived in Section 2. $2^{\text {nd }}$ order reduced polynomial hyperelastic model was found to be the most suitable with the highest accuracy, fewer parameters, and shorter computational time requirements. The experimental data and fitted model of $2^{\text {nd }}$ order reduced polynomial is shown in Figure 5. An agreement exists between the two shown curves as the following. 


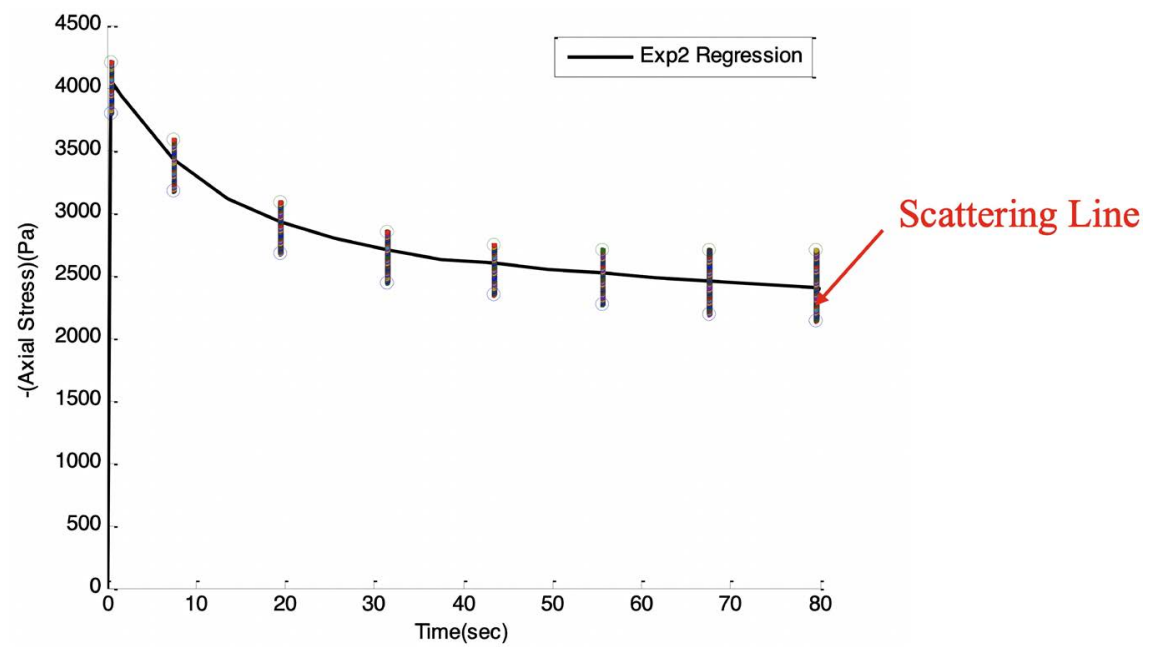

Figure 4. Experimental results for relaxation of brain tissue with $0.67 \mathrm{~s}^{-1}$ ramp rate and $80 \mathrm{sec}$. hold time.

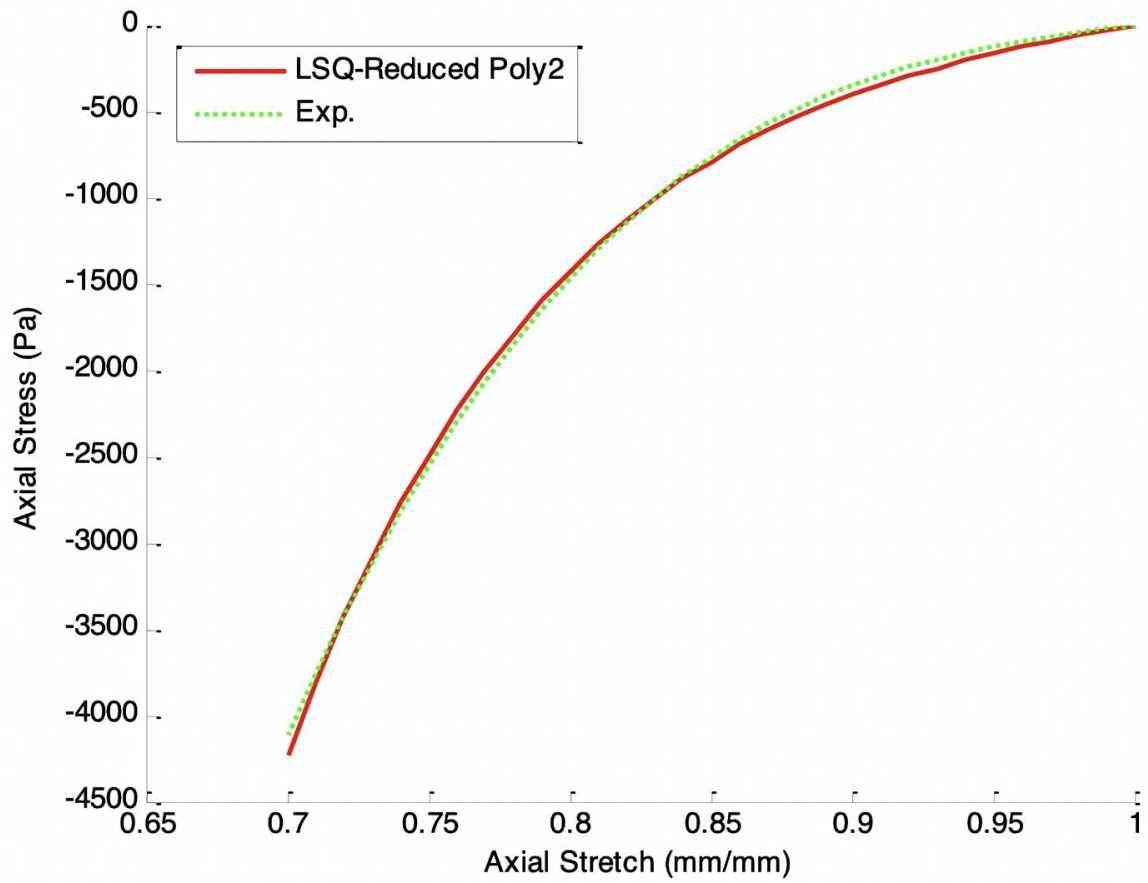

Figure 5. Experimental (green dotted line) and theoretical (solid red line) engineering stresses at each stretch.

The parameters of $2^{\text {nd }}$ order reduced polynomial hyperelastic model, and the coefficient of determination $\left(R^{2}\right)$ is tabulated in Table 2.

Using Equation (3), the initial shear modulus is $G_{0}=1.0162 \mathrm{kPa}$. In similar research by Miller and Chinzei (2002) [65] and Rashid et al. (2013) [60], the initial shear modulus is shown to be $G_{0}=0.842 \mathrm{kPa}$ and $G_{0}=1.038 \mathrm{kPa}$, respectively. In the present study, Drucker stability criteria are considered in the parameters extraction of strain energy function while most previous studies such as Refs. [44] [65] [67] [68] [69] have not considered this important criterion. 
Table 2. The parameters of $2^{\text {nd }}$ order reduced polynomial hyperelastic model.

\begin{tabular}{ccc}
\hline$C_{10}(\mathrm{~Pa})$ & $C_{20}(\mathrm{~Pa})$ & $R^{2}$ \\
\hline 508.1 & 1537.4 & 0.9992 \\
\hline
\end{tabular}

\subsection{Fitting of Prony Series Model to Relaxation Test Result}

According to Quasi-linear viscoelastic (QLV) theory, the normalized shear modulus is independent of strain up to $30 \%$ strain [70]. In this research, the linear viscoelastic theory was used, and it was shown that at least two terms of the In fact, the Prony series (Equation (6)) are needed to capture the material relaxation behavior accurately. Two terms of the Prony series parameters and coefficient of determination $\left(R^{2}\right)$ are tabulated in Table 2 and calibrated by lsqcurvefit function.

The parameters in Table 2 and Table 3 can be directly used in finite element commercial software such as ABAQUS ${ }^{\circledR}$ or ANSYS ${ }^{\circledR}$.

\subsection{Finite Element Analysis}

In this section, the results of the finite element analysis are compared with experimental data. In order to carry out finite element analysis, two parts include top and lower rigid parts as top and lower platens, and a deformable part as a brain specimen is created in ABAQUS ${ }^{\circledR}$ Finite Element Analysis (FEA) software. The property of deformable part (brain specimen) was assigned according to Table 2 and Table 3. The number of nodes and the number of elements are 3990 and 3380, respectively, and element type are C3D8R (a 8-linear node brick reduced integration hourglass energy). Meshed assembly parts in ABAQUS ${ }^{\circledR}$ FEA are shown in Figure 6. Mesh convergence tests were performed to validate the mesh density used, and hourglass energy analysis was conducted to evaluate all FE simulations' integrity.

It is noticeable in all FE simulations for unconfined compression tests, relaxation tests, and ramp rate variation on the relaxation test, the friction coefficient hypothesized to be $\mu=0.1$ [69] [71]. The effect of friction coefficient and ramp rate in the relaxation test are studied. FE simulations of unconfined compression tests at three velocities are depicted in Figures 7(a)-(c).

As shown in this Figure 8, the relative error between experimental and FE simulation decreases as strain rate increases. These phenomena can be owing to the elimination of the viscoelastic effect at a high strain rate. FE simulation of relaxation test is presented in Figure 10. This figure indicates that a reasonable agreement exists between experimental and FE simulations.

Figure 9(b) and Figure 9(a) present the variation of ramp rate on the relaxation test using finite element analysis. FE simulation was conducted for three ramp rates of 1,10 , and $450 \mathrm{~ms}$.

From Figure 9, it is evident that the ramp rate has little effect on normalized shear modulus. The relative difference between ramp rates of 1 and $450 \mathrm{~ms}$ is about $4.6 \%$. Effect of the friction coefficient between the top and bottom platen 
Table 3. Two terms of the Prony series parameters.

\begin{tabular}{ccccc}
\hline$g_{1}$ & $g_{2}$ & $\tau_{1}(\mathrm{sec})$ & $\tau_{2}(\mathrm{sec})$ & $R^{2}$ \\
\hline 0.08 & 0.39 & 0.02 & 19.71 & 0.9995 \\
\hline
\end{tabular}

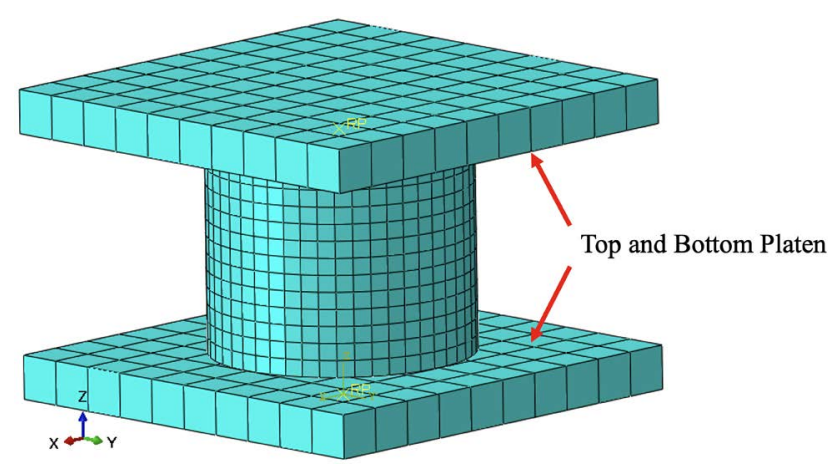

Figure 6. Meshed assembly parts in ABAQUS ${ }^{\circledR}$ FEA.

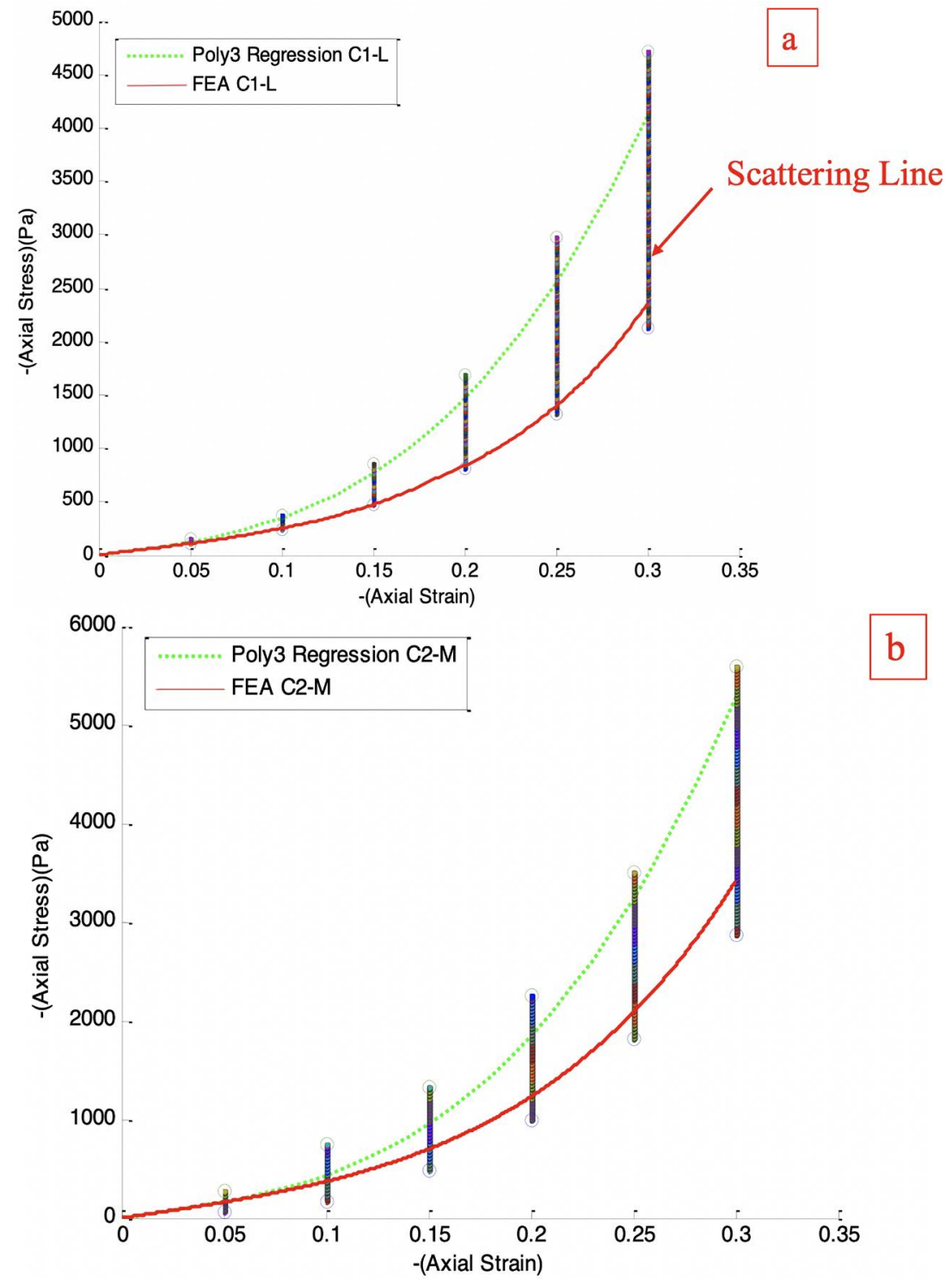




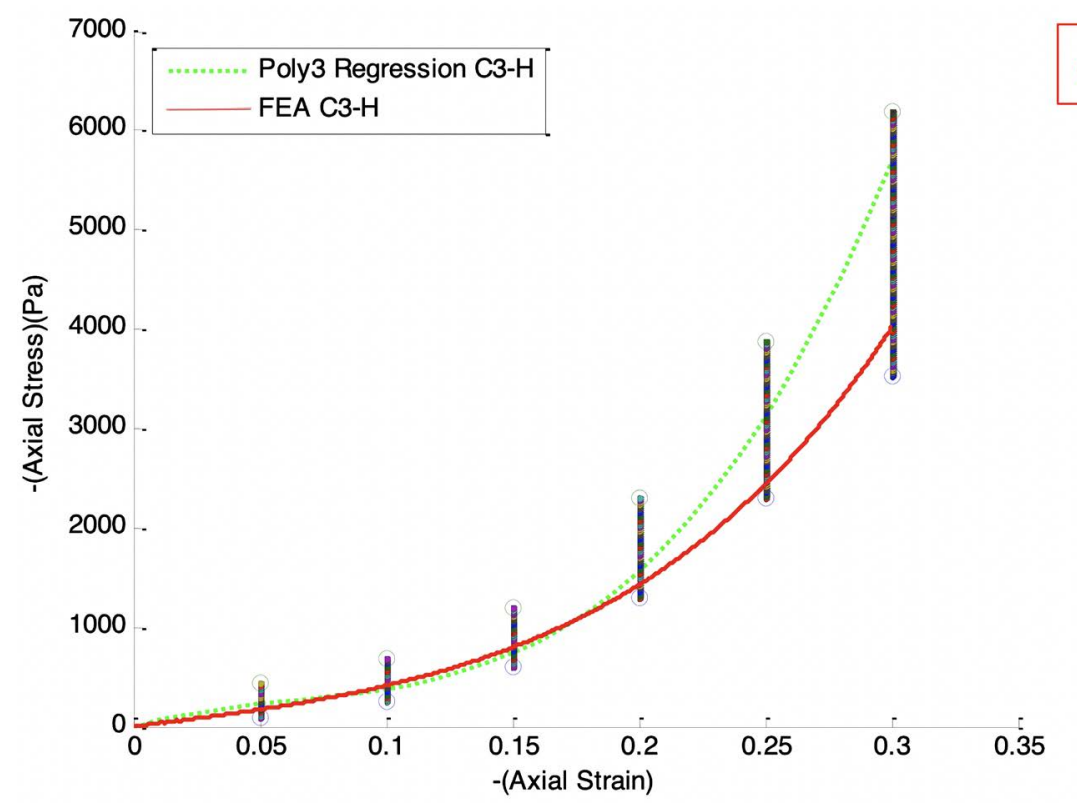

Figure 7. Comparisons of experimental (green dotted line) and finite element simulation (red solid line) engineering stress vs strain: (a) Loading velocity $0.6 \mathrm{~mm} / \mathrm{min}$ (slow), (b) Loading velocity $12 \mathrm{~mm} / \mathrm{min}$ (medium), (c) Loading velocity $600 \mathrm{~mm} / \mathrm{min}$ (fast).

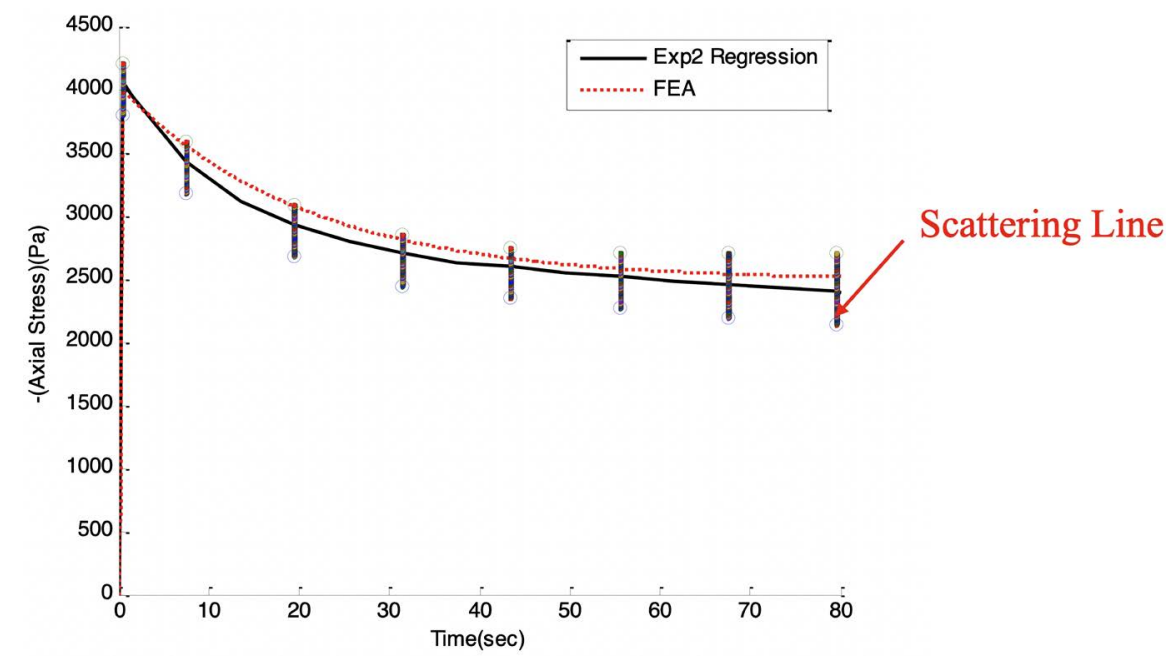

Figure 8. Results of experimental (solid black line) and FE simulation (red dotted line) engineering stresses vs. time.

with cylindrical brain specimen at a speed of $600 \mathrm{~mm} / \mathrm{min}$ in unconfined compression test are investigated using finite element analysis. The findings of the simulation and experiment are shown in Figure 10. As can be seen in Figure 10, as the friction coefficient increases, the difference between numerical and experimental results for the associated stress reduces. The relative difference between simulation results at a friction coefficient of $\mu=0.5$ and $\mu=0$ is less than $20 \%$.

Figure 11 presents stress distribution in the cylindrical brain specimen at a speed of $600 \mathrm{~mm} / \mathrm{min}$ in an unconfined compression test for two different friction coefficients. 

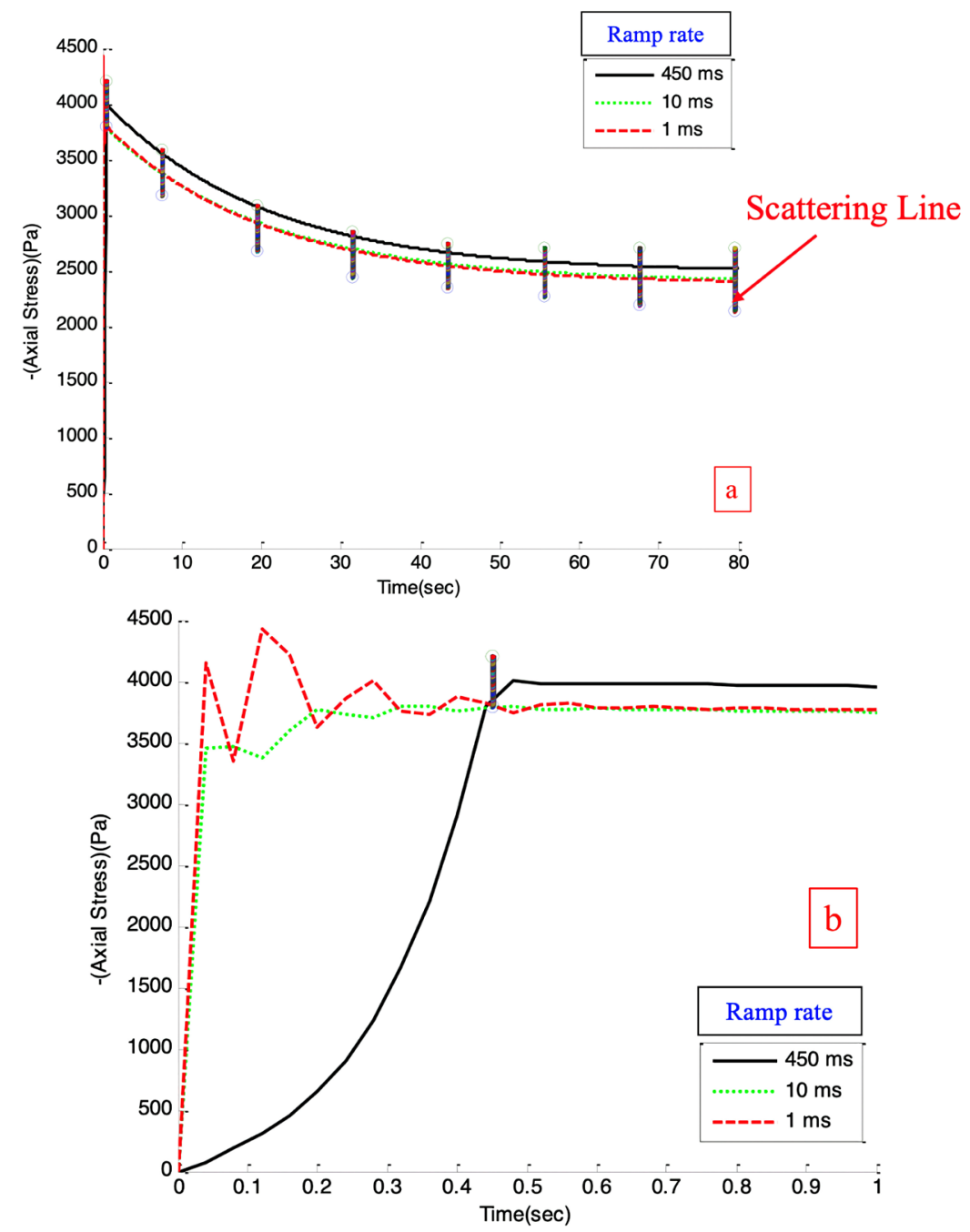

Figure 9. Effect of ramp rate variation on relaxation test.

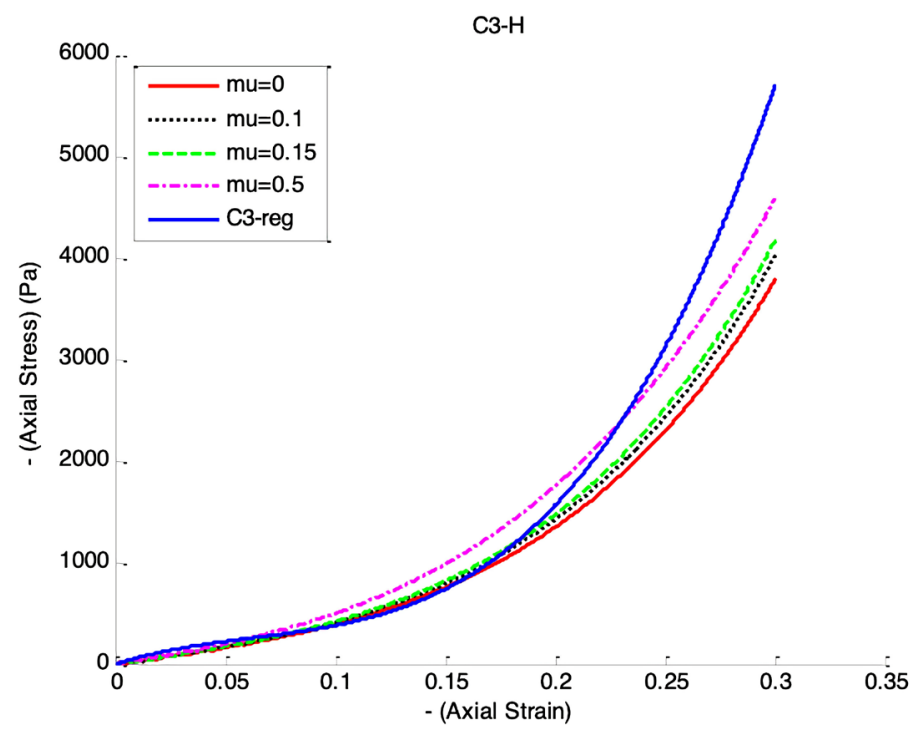

Figure 10. Effect of friction coefficient on stress-strain curve at strain rate of 600 $\mathrm{mm} / \mathrm{min}$ in unconfined compression test. 


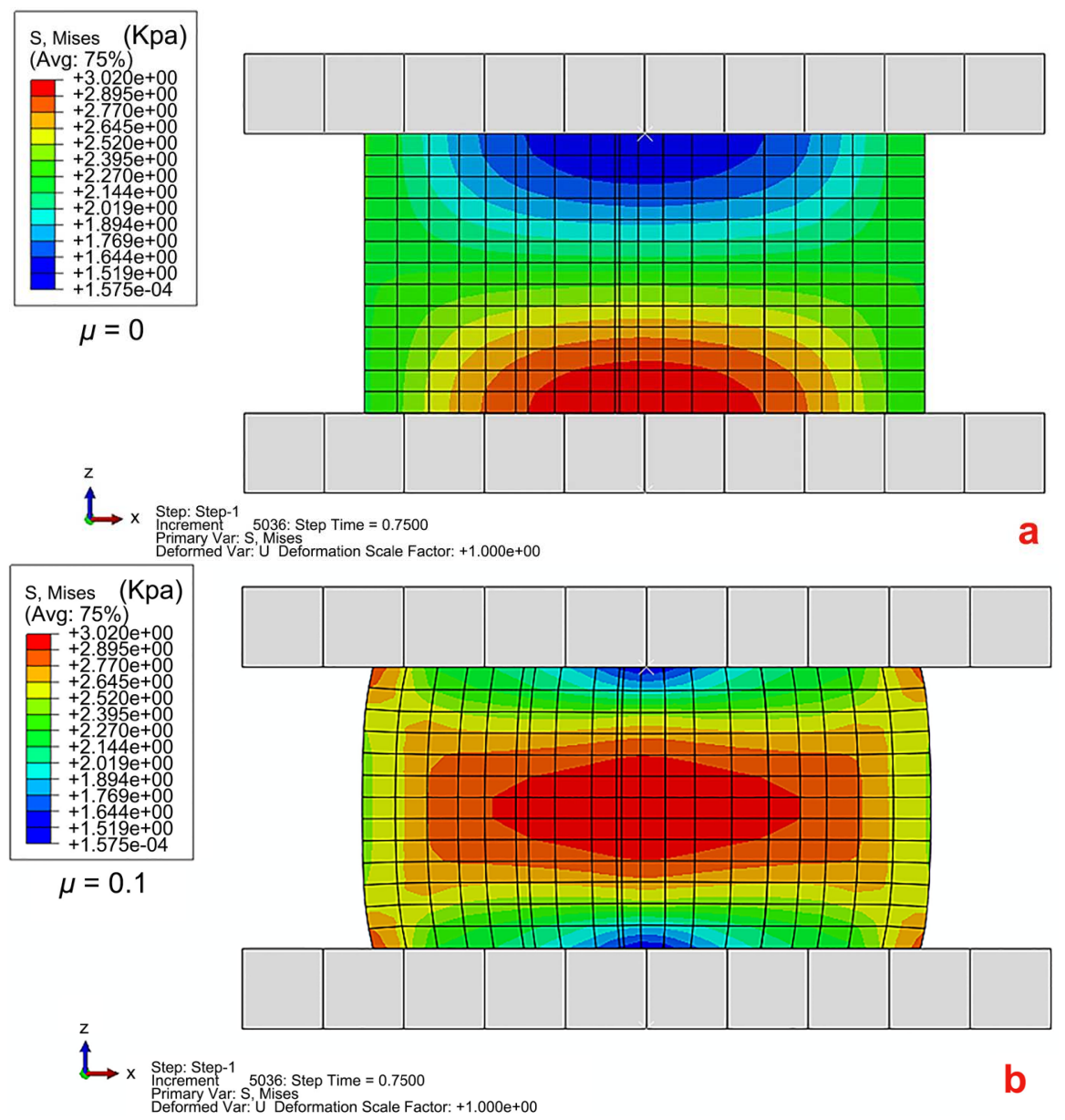

Figure 11. The influence of friction coefficient on stress and displacement distribution (a) frictionless (b) $\mathrm{mu}=0.1$.

It is clear that as friction coefficient increases, stress and displacement distribution become non-uniform.

\section{6. $+G_{Z}$ Accelerations}

Brain damage criteria such as HIC and Maximum Brain Pressure are evaluated at different $+G_{z}$ acceleration using the 3D model. Developed 3D FE model was subjected to $+G_{z}$ that is a squared sinusoidal pulse $\left(\sin ^{2}\right)$ with an amplitude of $a_{0}$ and duration of $T$. The equation of the pulse may be written as:

$$
a=a_{0}\left(\sin ^{2} \frac{\pi}{T} t\right)
$$

The maximum velocity $V_{\max }$ occurs at time $T$ and $V_{\max }=\frac{a_{0} T}{2}$. The HIC criteria may be defined as follows [72] in Equation (12):

$$
\text { HIC }=\max \left(\left[t_{2}-t_{1}\right]\left[\frac{1}{t_{2}-t_{1}} \int_{t_{1}}^{t_{2}} a(t) \mathrm{d}(t)\right]^{2.5}\right)
$$

then: 


$$
\mathrm{HIC}=T\left(\frac{a_{0}}{2}\right)^{2.5}=T\left(\frac{v_{\max }}{T}\right)^{2.5}=v_{\max }\left(\frac{a_{0}}{2}\right)^{1.5}
$$

Scott et al. (2012) presented the threshold of $+G_{z}$-induced Loss of Consciousness (G-LOC) curve from physiologist's perspective (Figure 12) [73]. While G-LOC was induced by $+G_{z}$ stress, the G-LOC curves were developed for prediction according to a theoretical concept in which acceleration influences underlying physiological mechanisms affording tolerance to acceleration, their limitations, and what happens when they are exceeded. A minimal dataset of sign and symptom endpoints led to the basis of previous $+G_{z}$-time tolerance curves [74]. In order to express G-LOC threshold based on HIC and Maximum Brain Pressure criteria, Equation (13) and 3D FE model simulations were used, respectively. At selected points (Red points) of acceleration and time (Figure 12), the related maximum brain pressure was evaluated by our 3D FE model simulations.

\subsection{Three-Dimensional Configuration of Loss of Consciousness Threshold}

Critical points of loss of consciousness at a specific amplitude and time duration (Figure 12) are specified based on maximum brain pressure as indicated on third axes of loss of consciousness threshold domain (Figure 13). Similarly, loss of consciousness threshold may be presented in a 3D domain with HIC criteria as the third axis (Figure 14).

From Figure 13 and Figure 14, it is evident that Max. Brain Pressure $3.1 \mathrm{KPa}$ and HIC 30 are a representation of loss of consciousness. For example, pressure on the entire brain at the time of $t=3 \mathrm{Sec}$. at point $\mathrm{F}$ (acceleration of $4 \mathrm{G}$ and time duration of $T=6 \mathrm{Sec}$.) is shown in Figure 15.

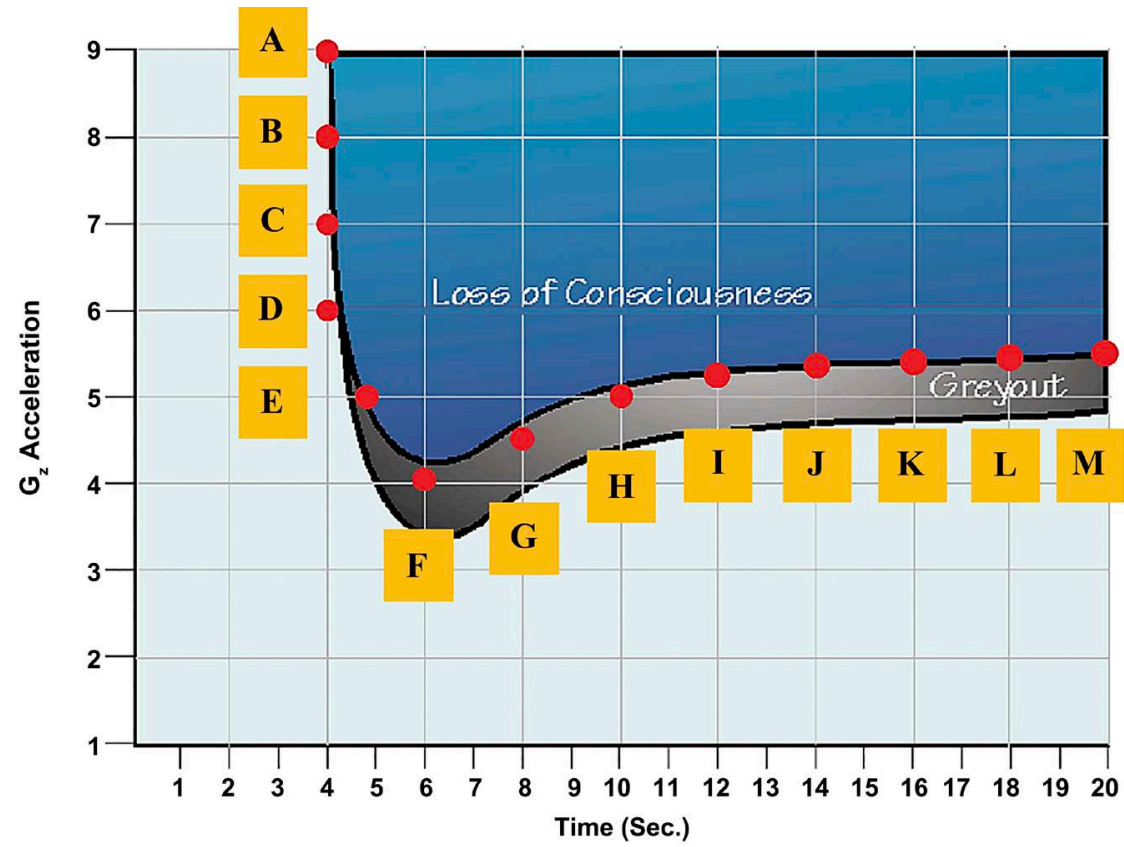

Figure 12. G-LOC tolerance curve [73]. 


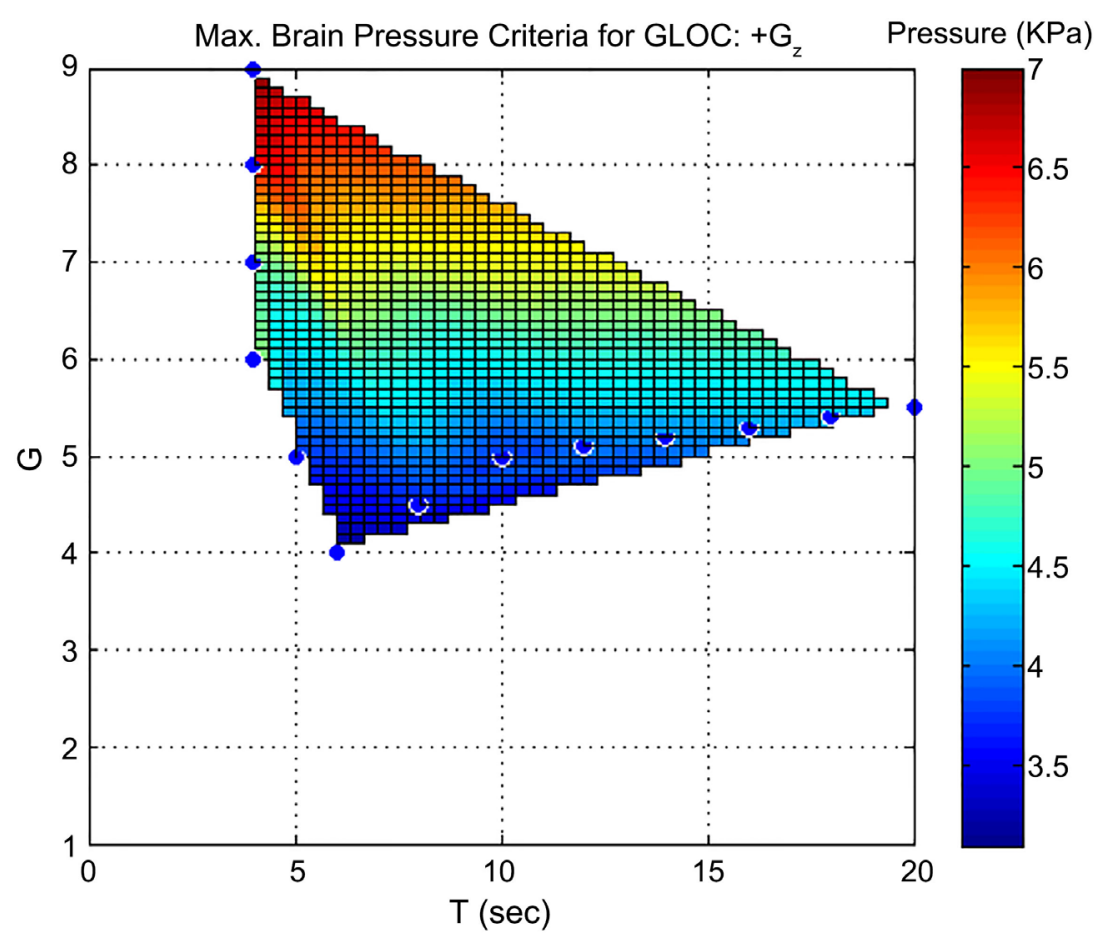

Figure 13. Maximum brain pressure induced $+G_{z}$ acceleration.

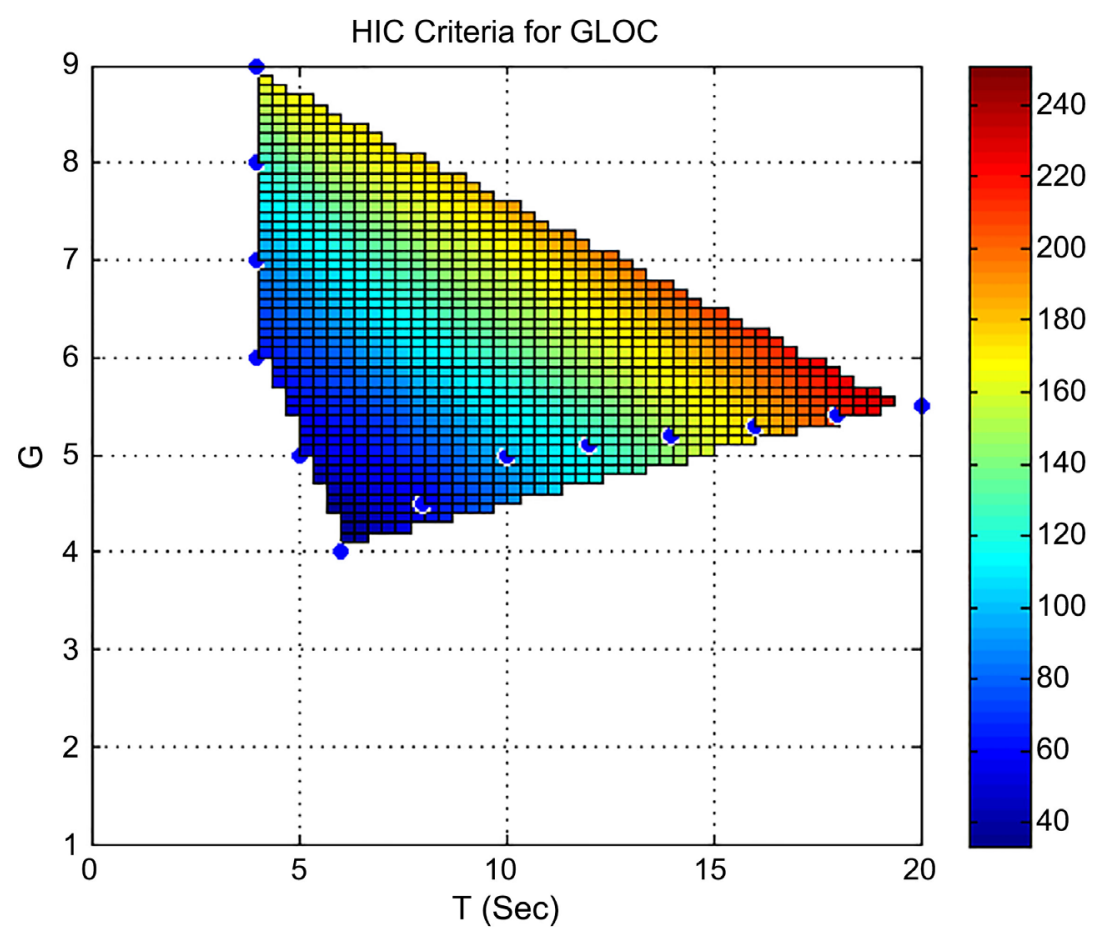

Figure 14. HIC criteria for GLOC.

A study of the previous investigations indicates a loss of consciousness addressed qualitatively by the researchers and rarely quantifies through an engineering perspective. In the present study, two 3D dimensional domains are developed for Max. Brain Pressure and Loss of consciousness criteria. 


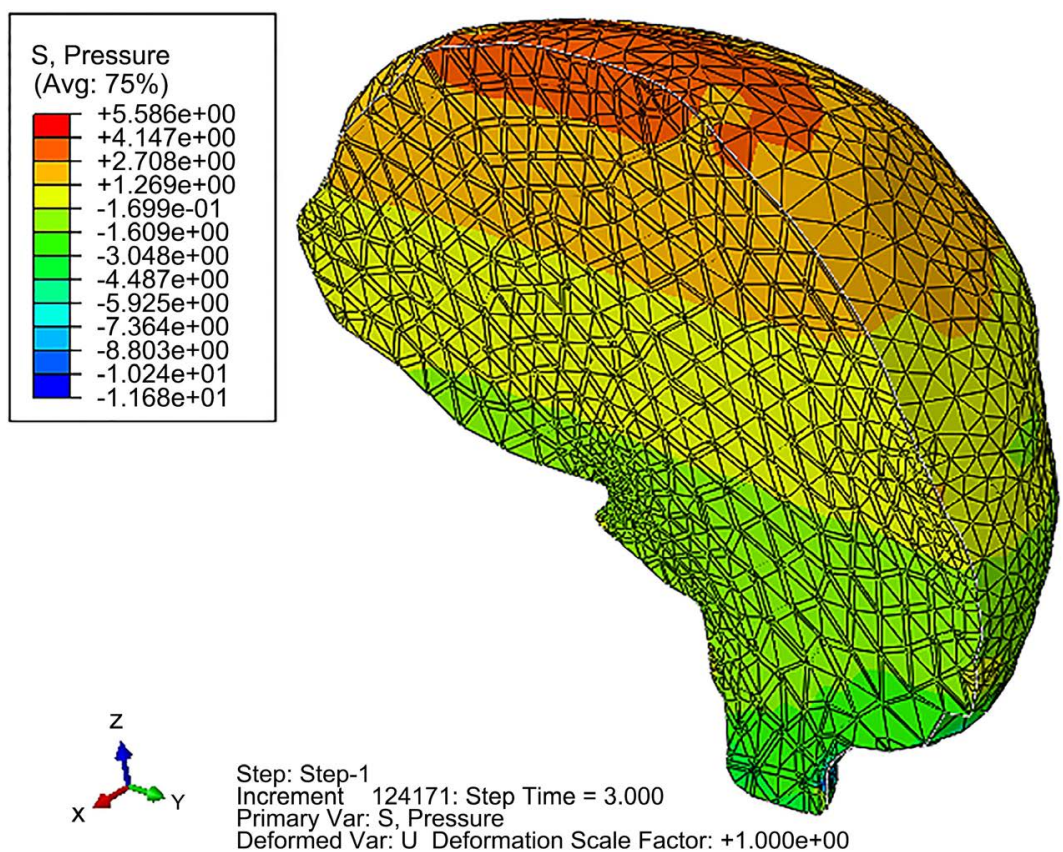

Figure 15. Pressure (KPa) in the entire brain at the time of $t=3 \mathrm{~s}$ on point $\mathrm{F}$ (acceleration of $4 \mathrm{G}$ and time duration of $T=6 \mathrm{Sec}$.).

\section{Conclusions}

This study highlights the importance of strain rate effects on brain trauma under finite deformation. In this regard, experimental setup on brain tissue was developed to perform unconfined compression tests at quasi-static strain rates of $\dot{\varepsilon}=0.0004 \mathrm{~s}^{-1}, \dot{\varepsilon}=0.008 \mathrm{~s}^{-1}$, and $\dot{\varepsilon}=0.4 \mathrm{~s}^{-1}$ and a stress relaxation test under unconfined uniaxial compression with a $\dot{\varepsilon}=0.67 \mathrm{~s}^{-1}$ ramp rate. We found that the $2^{\text {nd }}$ order reduced polynomial hyperelastic model is favorable among different hyperelastic models due to its accuracy, fewer parameters, and shorter computational time requirements. Drucker stability criterion has been utilized to extract parameters of the strain energy function. Also, the obtained parameters can be directly used in any commercial finite element software. Finite element simulation is conducted based on an experimental setup. Conducting ramp rate effects on the relaxation test indicates that the ramp rate variation has a slight effect on normalized shear modulus. Finally, it has been shown that the relative difference between simulation results at a friction coefficient of $\mu=0.5$ and $\mu=0$ is less than $20 \%$.

Moreover, a 3D head model, constructed based on a human head's real data, was used to apply $+G_{z}$ accelerations, thus obtaining maximum brain pressure. The threshold of loss of consciousness arising from $+G_{z}$ acceleration considering brain damage criteria such as HIC and maximum brain pressure is presented. Results revealed that the Maximum Brain Pressure $\geq 3.1 \mathrm{KPa}$ and $\mathrm{HIC} \geq 30$ are a representation of loss of consciousness. Finally, two 3D domains were developed for the loss of consciousness, according to Max. Brain Pressure and the HIC criteria. 


\section{Acknowledgements}

The first author would like to sincerely thank Dr. M.T. Ahmadian. This work would not have been possible without his scientific supports.

\section{Conflicts of Interest}

The authors declare no conflicts of interest regarding the publication of this paper.

\section{References}

[1] Peterson, A.B., Xu, L.K., Daugherty, J. and Breiding, M.J. (2019) Surveillance Report of Traumatic Brain Injury-Related Emergency Department Visits, Hospitalizations, and Deaths, United States, 2014.

[2] Sigurdardottir, S., Andelic, N., Wehling, E., Anke, A., Skandsen, T., Holthe, O.O., Manskow, U.S. and Roe, C. (2020) Return to Work after Severe Traumatic Brain Injury: A National Study with a One-Year Follow-Up of Neurocognitive and Behavioural Outcomes. Neuropsychological Rehabilitation, 30, 281-297. https://doi.org/10.1080/09602011.2018.1462719

[3] Domel, A.G., Raymond, S.J., Giordano, C., Liu, Y.Z., Yousefsani, S.A., Fanton, M., Cecchi, N.J., Vovk, O., Pirozzi, I., Kight, A., et al. (2021) A New Open-Access Platform for Measuring and Sharing mTBI Data. Scientific Reports, 11, Article No. 7501. https://doi.org/10.1038/s41598-021-87085-2

[4] Akparibo, I.Y. and Chumbley, E. (2017) Aerospace, Gravitational Effects, High Performance.

[5] Khezrloo, A., Tayebi, M., Shafiee, A. and Aghaie, A. (2021) Evaluation of Compressive and Split Tensile Strength of Slag Based Aluminosilicate Geopolymer Reinforced by Waste Polymeric Materials Using Taguchi Method. Materials Research Express, 8, Article ID: 025504. https://doi.org/10.1088/2053-1591/abe101

[6] Shafiee, A., Mosadegh, P., Bashash, S., et al. (2014) Study of Cross-Coupling Effect in Piezoflexural Nanopositioning Stages. Modares Mechanical Engineering, 14, 1-8.

[7] Ahmadian, A., Shafiee, A., Alidoost, M. and Akbari, A. (2021) Flexible Paper-Based Li-Ion Batteries: A Review. World Journal of Engineering and Technology, 9, 285. https://doi.org/10.4236/wjet.2021.92020

[8] Shafiee, A., Ahmadian, A. and Akbari, A. (2021) A Parametric Study of Mechanical Cross-Coupling in Parallel-Kinematics Piezo-Flexural Nano-Positioning Systems. World Journal of Engineering and Technology, 11, 596-613. https://doi.org/10.4236/ojapps.2021.115043

[9] Bazmara, M., Silani, M. and Dayyani, I. (2021) Effect of Functionally-Graded Interphase on the Elasto-Plastic Behavior of Nylon-6/Clay Nanocomposites: A Numerical Study. Technology, 17, 177-184.

[10] Hoursan, H., Farahmand, F. and Ahmadian, M.T. (2021) Effect of Axonal Fiber Architecture on Mechanical Heterogeneity of the White Matter-A Statistical Micromechanical Model. Computer Methods in Biomechanics and Biomedical Engineering, 1-13. https://doi.org/10.1080/10255842.2021.1927000

[11] Jiang, F.F., Roberts, W.E., Liu, Y.Z., Shafiee, A. and Chen, J. (2020) Mechanical Environment for Lower Canine T-Loop Retraction Compared to En-masse Space Closure with a Power-Arm Attached to Either the Canine Bracket or the Archwire. The Angle Orthodontist, 90, 801-810. https://doi.org/10.2319/050120-377.1 
[12] Farhang, B., Araghi, F.R., Bahmani, A., Moztarzadeh, F. and Shafieian, M. (2016) Landing Impact Analysis of Sport Surfaces Using Three-Dimensional Finite Element Model. Proceedings of the Institution of Mechanical Engineers, Part P. Journal of Sports Engineering and Technology, 230, 180-185. https://doi.org/10.1177/1754337115591755

[13] Hossain, M.J., Noori-Dokht, H., Karnik, S., Alyafei, N., Joukar, A., Trippel, S.B. and Wagner, D.R. (2020) Anisotropic Properties of Articular Cartilage in an Accelerated in Vitro Wear Test. Journal of the Mechanical Behavior of Biomedical Materials, 109, Article ID: 103834. https://doi.org/10.1016/j.jmbbm.2020.103834

[14] Tavakol M. and Vaughan, T.J. (2020) The Structural Role of Osteocalcin in Bone Biomechanics and Its Alteration in Type-2 Diabetes. Scientific Reports, 10, Artic No. 17321.

[15] Shekouhi, N., et al. (2020) Clinically Relevant Finite Element Technique Based Protocol to Evaluate Growing Rods for Early Onset Scoliosis Correction. JOR Spine, 3, Aeticle ID: e1119.

[16] Akbari, A., Wang, D. and Chen, J. (n.d.) Peak Loads on Teeth from Generic Mouthpiece of Vibrational Device for Accelerating Tooth Movement. American Journal of Orthodontics and Dentofacial Orthopedics.

[17] Shekouhi, N., DD, B.M.W., Kaeley, D.K. and Goel, V.K. (2020) Finite Element Based Test Protocol to Evaluate the Effect of Distraction on Growth Rods Spanning over Multiple Spinal Segments for Pediatric Scoliosis Patients. ORS Annual Meeting.

[18] Sahoo, D., Robbe, C., Deck, C., Meyer, F., Papy, A. and Willinger, R. (2016) Head Injury Assessment of Non-Lethal Projectile Impacts: A Combined Experimental/Computational Method. Injury, 47, 2424-2441.

https://doi.org/10.1016/j.injury.2016.09.004

[19] Ozkaya, E., Fabris, G., Macruz, F., Suar, Z.M., Abderezaei, J., Su, B., Laksari, K., Wu, L., Camarillo, D.B., Pauly, K.B., Wintermark, M. and Kurt, M. (2021) Viscoelasticity of Children and Adolescent Brains through MR Elastography. Journal of the Mechanical Behavior of Biomedical Materials, 115, Article ID: 104229. https://doi.org/10.1016/j.jmbbm.2020.104229

[20] Budday, S., Sommer, G., Birkl, C., Langkammer, C., Haybaeck, J., Kohnert, J., Bauer, M., Paulsen, F., Steinmann, P., Kuhl, E., et al. (2017) Mechanical Characterization of Human Brain Tissue. Acta Biomaterialia, 48, 319-340.

https://doi.org/10.1016/j.actbio.2016.10.036

[21] Abderezaei, J., Pionteck, A., Terem, I., Dang, L., Scadeng, M., Morgenstern, P., Shrivastava, R., Holdsworth, S.J., Yang, Y. and Kurt, M. (2021) Development, Calibration, and Testing of 3d Amplified MRI (AMRI) for the Quantification of Intrinsic Brain Motion. Brain Multiphysics, Article ID: 100022.

https://doi.org/10.1016/j.brain.2021.100022

[22] Lee, W., Moghaddam, A.O., Shen, S., Phillips, H., McFarlin, B.L., Johnson, A.W. and Toussaint Jr., K.C. (2021) An Optomechanogram for Assessment of the Structural and Mechanical Properties of Tissues. Scientific Reports, 11, Article No. 324. https://doi.org/10.1038/s41598-020-79602-6

[23] Moghaddam, A.O., Wei, J., Kim, J., Dunn, A.C. and Johnson, A.W. (2020) An Indentation-Based Approach to Determine the Elastic Constants of Soft Anisotropic Tissues. Journal of the Mechanical Behavior of Biomedical Materials, 103, Article No. 103539. https://doi.org/10.1016/j.jmbbm.2019.103539

[24] Arefi, M., Nasr, M. and Loghman, A. (2018) Creep Analysis of the fg Cylinders: 
Time-Dependent Nonaxisymmetric Behavior. Steel and Composite Structures, 28, 331-347.

[25] Rahmati, A.H. and Mohammadimehr, M. (2014) Vibration Analysis of Non-Uniform and Non-Homogeneous Boron Nitride Nanorods Embedded in an Elastic Medium under Combined Loadings Using DQM. Physica B: Condensed Matter, 440, 88-98. https://doi.org/10.1016/j.physb.2014.01.036

[26] Arani, A.G., Abdollahian, M., Kolahchi, R. and Rahmati, A.H. (2013) Electro-Thermo-Torsional Buckling of an Embedded Armchair DWBNNT Using Nonlocal Shear Deformable Shell Model. Composites Part B: Engineering, 51, 291-299. https://doi.org/10.1016/j.compositesb.2013.03.017

[27] Jafarzadeh, H. and Mansoori, H. (2020) Phase Field Approach to Mode-I Fracture by Introducing an Eigen Strain Tensor: General Theory. Theoretical and Applied Fracture Mechanics, 108, Article ID: 102628.

https://doi.org/10.1016/j.tafmec.2020.102628

[28] Mortazavian, E., Wang, Z.Y. and Teng, H.L. (2021) Effect of Heat Treatment on Microstructure and Hardness of a Worn Rail Repaired Using Laser Powder Deposition. International Journal of Transportation Science and Technology. https://doi.org/10.1016/j.ijtst.2021.05.004

[29] Maghsoudi-Ganjeh, M., Samuel, J., Ahsan, A.S., Wang, X.D. and Zeng, X.W. (2021) Intrafibrillar Mineralization Deficiency and Osteogenesis Imperfecta Mouse Bone Fragility. Journal of the Mechanical Behavior of Biomedical Materials, 117, Article ID: 104377. https://doi.org/10.1016/j.jmbbm.2021.104377

[30] Alizadeh, V. and Tahani, M. (2015) Nonlinear Viscoelastic Dynamic Modeling of High-Speed Polypyrrole-Based Trilayer Bending Plate-Like Actuators Based on First-Order Shear Deformation Plate Theory. Journal of Intelligent Material Systems and Structures, 26, 292-308. https://doi.org/10.1177/1045389X14525489

[31] Ehsani, A. and Pahlavan, L. (2009) Finite Element Modeling of Active Vibration Control of IPMC Beams. International Review of Automatic Control, 2, 491-496.

[32] Moheimani, R., Aliahmad, N., Aliheidari, N., Agarwal, M. and Dalir, H. (2021) Thermoplastic Polyurethane Flexible Capacitive Proximity Sensor Reinforced by CNTs for Applications in the Creative Industries. Scientific Reports, 11, Article No. 1104. https://doi.org/10.1038/s41598-020-80071-0

[33] Andalib, V. and Sarkar, J. (2019) A Repairable System Supported by Two Spare Units and Serviced by Two Types of Repairers.

[34] McCarty, A. (2020) Mechanics of Blast-Induced Traumatic Brain Injury in Porcine Brain Tissue.

[35] Menichetti, A., MacManus, D.B., Gilchrist, M.D., Depreitere, B., Sloten, J.V. and Famaey, N. (2020) Regional Characterization of the Dynamic Mechanical Properties of Human Brain Tissue by Microindentation. International Journal of Engineering Science, 155, Article ID: 103355. https://doi.org/10.1016/j.ijengsci.2020.103355

[36] Li, Z.G., Yang, H.F., Wang, G.L., Han, X.Q. and Zhang, S.P. (2019) Compressive Properties and Constitutive Modeling of Different Regions of 8-Weekold Pediatric Porcine Brain under Large Strain and Wide Strain Rates. Journal of the Mechanical Behavior of Biomedical Materials, 89, 122-131. https://doi.org/10.1016/j.ijengsci.2020.103355

[37] Mihai, L.A., Budday, S., Holzapfel, G.A., Kuhl, E. and Goriely, A. (2017) A Family of Hyperelastic Models for Human Brain Tissue. Journal of the Mechanics and Physics of Solids, 106, 60-79. https://doi.org/10.1016/j.jmps.2017.05.015 
[38] Zhao, W., Choate, B. and Ji, S.B. (2018) Material Properties of the Brain in Injury-Relevant Conditions-Experiments and Computational Modeling. Journal of the Mechanical Behavior of Biomedical Materials, 80, 222-234. https://doi.org/10.1016/j.jmbbm.2018.02.005

[39] Teferra, K. and Brewick, P.T. (2019) A Bayesian Model Calibration Framework to Evaluate Brain Tissue Characterization Experiments. Computer Methods in Applied Mechanics and Engineering, 357, Article ID: 112604. https://doi.org/10.1016/j.cma.2019.112604

[40] Ruan, J.S., Khalil, T. and King, A.I. (1994) Dynamic Response of the Human Head to Impact by Three-Dimensional Finite Element Analysis. Journal of Biomechanical Engineering, 116, 44-50. https://doi.org/10.1115/1.2895703

[41] Zhang, J.Y., Yoganandan, N., Pintar, F.A. and Gennarelli, T.A. (2006) Role of Translational and Rotational Accelerations on Brain Strain in Lateral Head Impact. Biomedical Sciences Instrumentation, 42, 501-506.

[42] Shi, L.L., Han, Y., Huang, H.W., Davidsson, J. and Thomson, R. (2020) Evaluation of Injury Thresholds for Predicting Severe Head Injuries in Vulnerable Road Users Resulting from Ground Impact via Detailed Accident Reconstructions. Biomechanics and Modeling in Mechanobiology, 1-19. https://doi.org/10.1007/s10237-020-01312-9

[43] Pasquesi, S.A. and Margulies, S.S. (2018) Measurement and Finite Element Model Validation of Immature Porcine Brain-Skull Displacement during Rapid Sagittal Head Rotations. Frontiers in Bioengineering and Biotechnology, 6, 16. https://doi.org/10.3389/fbioe.2018.00016

[44] Nicolle, S., Lounis, M. and Willinger, R. (2004) Shear Properties of Brain Tissue over a Frequency Range Relevant for Automotive Impact Situations: New Experimental Results. Technical Report, SAE Technical Paper.

https://doi.org/10.4271/2004-22-0011

[45] Pervin, F. and Chen, W.N. (2011) Effect of Inter-Species, Gender, and Breeding on the Mechanical Behavior of Brain Tissue. NeuroImage, 54, S98-S102. https://doi.org/10.1016/j.neuroimage.2010.03.077

[46] Shafiee, A., Ahmadian, M.T. and Hoviattalab, M. (2016) Mechanical Characterization of Brain Tissue in Compression. International Design Engineering Technical Conferences and Computers and Information in Engineering Conference, Volume 50138, V003T11A001.

[47] Shafiee, A., Ahmadian, M.T., Hoursan, H. and Talab, M.H. (2015) Effect of Linear and Rotational Acceleration on Human Brain. Modares Mechanical Engineering, $15,248-260$.

[48] Eskandari, F., Shafieian, M., Aghdam, M.M. and Laksari, K. (2021) Structural Anisotropy vs. Mechanical Anisotropy: The Contribution of Axonal Fibers to the Material Properties of Brain White Matter. Annals of Biomedical Engineering, 49, 991-999. https://doi.org/10.1007/s10439-020-02643-5

[49] Eskandari, F., Rahmani, Z. and Shafieian, M. (2021) The Effect of Large Deformation on Poisson's Ratio of Brain White Matter: An Experimental Study. Proceedings of the Institution of Mechanical Engineers, Part H: Journal of Engineering in Medicine, 235, 401-407. https://doi.org/10.1177/0954411920984027

[50] Eskandari, F., Shafieian, M., Aghdam, M.M. and Laksari, K. (2021) Tension Strain-Softening and Compression Strain-Stiffening Behavior of Brain White Matter. Annals of Biomedical Engineering, 49, 276-286.

https://doi.org/10.1007/s10439-020-02541-w 
[51] Shuck, L.Z. and Advani, S.H. (1972) Rheological Response of Human Brain Tissue in Shear. Journal of Basic Engineering, 94, 905-911. https://doi.org/10.1115/1.3425588

[52] ANSYS Inc. (2012) ANSYS Fluent User's Guide. Version 14.5.

[53] Ogden, R.W. (1997) Non-Linear Elastic Deformations. Courier Corporation, Chelmsford.

[54] Drucker, D.C. (1957) A Definition of Stable Inelastic Material. Technical Report, Brown Univ., Providence. https://doi.org/10.21236/AD0143756

[55] Shafiee, A., Ahmadian, M.T. and Hoviattalab, M. (2016) Traumatic Brain Injury Caused by+ Gz Acceleration. International Design Engineering Technical Conferences and Computers and Information in Engineering Conference, Volume 50138, V003T11A002.

[56] Shafiee, A., Ahmadian, M.T., Hoursan, H. and Hoviattalab, M. (2014) Two-Dimensional Modeling and Analysis of the Effect of Linear Acceleration on Brain Strain Field in Traumatic Brain Injury. 22nd Annual International Conference on Mechanical Engineering, Athens, 19-22 July 2021, 22-29.

[57] Werchan, P.M. (1991) Physiologic Bases of g-Induced Loss of Consciousness (g-loc). Aviation, Space, and Environmental Medicine, 62, 612-614.

[58] Wood, E.H., Nolan, A.C., Donald, D.E. and Cronin, L. (1963) Influence of Acceleration on Pulmonary Physiology. Federation Proceedings, Volume 22, 1024.

[59] Chatelin, S., Deck, C., Renard, F., Kremer, S., Heinrich, C., Armspach, J.-P. and Willinger, R. (2011) Computation of Axonal Elongation in Head Trauma Finite Element Simulation. Journal of the Mechanical Behavior of Biomedical Materials, 4 , 1905-1919. https://doi.org/10.1016/j.jmbbm.2011.06.007

[60] Nahum, A.M., Smith, R. and Ward, C.C. (1977) Intracranial Pressure Dynamics during Head Impact. Technical Report, SAE Technical Paper. https://doi.org/10.4271/770922

[61] Chen, Y. and Ostoja-Starzewski, M. (2010) MRI-Based Finite Element Modeling of Head Trauma: Spherically Focusing Shear Waves. Acta Mechanica, 213, 155-167. https://doi.org/10.1007/s00707-009-0274-0

[62] Kleiven, S. and von Holst, H. (2002) Consequences of Head Size Following Trauma to the Human Head. Journal of Biomechanics, 35, 153-160. https://doi.org/10.1016/S0021-9290(01)00202-0

[63] Kleiven, S. (2003) Influence of Impact Direction on the Human Head in Prediction of Subdural Hematoma. Journal of Neurotrauma, 20, 365-379. https://doi.org/10.1089/089771503765172327

[64] Curve Fitting Toolbox (2001) For Use with Matlab; [User's Guide]. MathWorks, Natick.

[65] Miller, K. and Chinzei, K. (2002) Mechanical Properties of Brain Tissue in Tension. Journal of Biomechanics, 35, 483-490. https://doi.org/10.1089/089771503765172327

[66] Rashid, B., Destrade, M. and Gilchrist, M.D. (2013) Mechanical Characterization of Brain Tissue in Simple Shear at Dynamic Strain Rates. Journal of the Mechanical Behavior of Biomedical Materials, 28, 71-85. https://doi.org/10.1016/j.jmbbm.2013.07.017

[67] Laksari, K., Shafieian, M. and Darvish, K. (2012) Constitutive Model for Brain Tissue under Finite Compression. Journal of Biomechanics, 45, 642-646. https://doi.org/10.1016/j.jbiomech.2011.12.023

[68] Karimi, A., Navidbakhsh, M., Beigzadeh, B. and Faghihi, S. (2014) Retracted: 
Hyperelastic Mechanical Behavior of Rat Brain Infected by Plasmodium Berghei Anka-Experimental Testing and Constitutive Modeling. International Journal of Damage Mechanics, 23, 857-871. https://doi.org/10.1177/1056789513514072

[69] Moran, R., Smith, J.H. and García, J.J. (2014) Fitted Hyperelastic Parameters for Human Brain Tissue from Reported Tension, Compression, and Shear Tests. Journal of Biomechanics, 47, 3762-3766. https://doi.org/10.1016/j.jbiomech.2014.09.030

[70] Fung, Y.C. and Skalak, R. (1981) Biomechanics: Mechanical Properties of Living Tissues. Journal of Biomechanical Engineering, 103, 231-298.

[71] Rashid, B., Destrade, M. and Gilchrist, M.D. (2012) Mechanical Characterization of Brain Tissue in Compression at Dynamic Strain Rates. Journal of the Mechanical Behavior of Biomedical Materials, 10, 23-38.

https://doi.org/10.1016/j.jmbbm.2012.01.022

[72] Lissner, H.R., Lebow, M. and Evans, F.G. (1960) Experimental Studies on the Relation between Acceleration and Intracranial Pressure Changes in Man. Surgery, Gynecology \& Obstetrics, 111, 329.

[73] Scott, J., Stevenson, A.T. and Lupa, H. (2012) Space Tourism: An Acceleration Physiologist's Perspective. Aviation, Space, and Environmental Medicine, 83, 1.

[74] Whinnery, T. and Forster, E.M. (2013) The+ Gz-Induced Loss of Consciousness Curve. Extreme Physiology \& Medicine, 2, Article No. 19.

https://doi.org/10.1186/2046-7648-2-19 